\title{
Brought Forth in Bringing Forth. The Inter-Actions and Products of a Collective Learning System
}

TOM KIEREN \& ELAINE SIMMT

University of Alberta (Canada)

We would like to respond to the paper by Fazio and Gallagher, "Supporting learning: An examination of two teacher development collectives" by pointing to features of interaction which make possible the co-emergence of a learning system and its products and a discussion of the role of the facilitator in such a system which arguably has decentralized control. We begin with an illustration drawing from the work of Davis and Simmt (2006). In the particular workshop from which the interaction below arises, 8 of 24 teachers who participated in a two-year study were presented with the following question taken from 101 Short Problems from EQUALS (Kerr Stenmark, 1995).

If you measured an object with 5 different rulers and got 5 different answers how would you know which one is correct?

The intent of the session facilitator in posing this question was for the group of teachers to explore the emergence of explanations in learner activity. However, the responses to 
the question generated a powerful example of teachers' meaning making and how the products of a learning collective co-emerge from interactions and joint meaning making activity of its members.

The teachers in this group had all taught measurement in some form to learners; thus there was redundancy in the teachers' lived experiences that one might anticipate would lead to some similarities in individual responses and would enable them to understand one another's ideas. Yet since some participants were elementary teachers and others secondary teachers there were differences in their experiences in teaching mathematics both in content and level of formalism. Hence one might anticipate diversity in the ideas produced.

Such a possibility for diversity was further sponsored by the facilitator suggesting that each participant work on the task by him or herself for a short period of time before sharing responses with a partner and then the group. In making this request the facilitator did not try to shape or control the individual ideas nor did she, while "chairing" the discussion, try to lead it in particular directions. This sharing allowed for the inter-action among participants and the opportunity for their ideas to "bump into one another". As suggested in earlier work by Davis and Simmt (2003) it is essential in a collective learning system that the constituent ideas be in a public domain since the emerging product of a learning system is knowledge.

The above paragraph provides some evidence that the conditions were in place to observe emergent phenomena (see Johnson, 2001): the individuals had the lived experiences to produce relevant responses to the task and leave evidence of their thinking in the public domain; they had capacity to take up and act on the actions and artifacts of others; and there was opportunity for inter-action among persons and ideas.

So what did happen?

What follows is only a small sequence from the session. While it appears that the first ideas to appear are quite similar to one another, might this be due to the redundancies in the lived histories with measurement? But even here there is evidence of on-going knowing actions by individuals as we observe the elaboration of ideas offered. We will pay particular attention to the mechanism by which the learning (cognitive) system emerges as well as the actions of the facilitator in that system. The transcript in Figure 1 picks up once the facilitator calls the group together to discuss their ideas. Recall the prompt for the teachers:

\section{If you measured an object with 5 different rulers and got 5 different answers how would you know which one is correct?}


Teacher 1:

Teacher 2:

Teacher 1:

10

Teacher 3:

Teacher 4:

Facilitator:
I think you need to compare the five measuring tools. Forget the object. You need to look at the measuring tools to see if there is some way to align them to get common markings on them. One is in inches, one is in centimeters one is in millimeters, one isn't in anything. You better compare what you are using to measure not question the object.

What are the five different answers... maybe one person gave the imperial measure one in metric, one in millimeters one in centimeters, millimeters. Maybe they are all equivalent.

Compare five different measuring tools. Align them to get common markings, centimeters, inches, millimeters.

I am working on the assumption that they gave you all of these measurements in one common unit. It is the actually tools they are using that may be a little off.

We talked about - if there are differences, where might the differences arise from the measurements? It might be the tools are a little wonky, or they might not be. If you are measuring a straight line your measuring stick might go up slightly or it might not start at zero. Or if you are using a tape measure it might not be taut. And it would depend on the precision of the measurements. Something if you are measuring to the nearest millimeter it might be more difficult than to the nearest centimeter. The margin for the errors at the beginning should be addressed - or the possibility for errors. If it is a height you are measuring, maybe your eye does not go straight up. Knowing were the errors would arise. How would you decide it is correct?

I would use my own estimation skills.

Facilitator: Before we go there are there any other things? I would like to talk about explanations. Notice when we have "why" questions this demands an explanation. Two things that commonly came up-- there is something wrong with the tool and there is something wrong with the person measuring, the measuring itself. Okay that is one level. Are there other examples from this that you can image?

Teacher 4: $\quad$ It might be the object too. If the object were flat it is easier. If it is a bumpy object then-

Facilitator: $\quad$ - so now we have the third possibility. This is a nice one. How long is the coastline of British Columbia? It is as much about the nature of the coastline as it is about the measurer and the measurement instrument. So there are these three things that come into play-

Teacher 6: $\quad$ - and the time of day you measure. [Group members burst out with laughter, nods and utterances of confirmation]

That's a nice one. The dynamic part too, the tide. That is a good one. That, right there. What happened? As a group we raised all these things. I marked - 'tool', 'person'. You came up with 'it depends on the object'. We are producing knowledge here as a collective when this sort of thing happens.

Figure 1. Transcript of a small sequence from the session 
Similar to the work of the two teacher development groups discussed by Fazio and Gallagher, even this short sequence of data (Figure 1) can be observed for its complexity and complicity and particularly for emergent knowledge. In observing such richly interactive settings in the past we have used ideas drawn together in a model created initially by Simmt (2000) to observe inter-active knowing of parent/child pairs working on mathematical problems. The version of the model shown in Figure 2, below, brings together and extends a number of ideas from the work of Maturana and Varela (e.g., 1987); in particular, their definition of knowing and structural coupling. A person brings forth a world of significance with others within a sphere of behavioural possibilities. When this whole system is observed by an observer (who can be in the system) patterns are distinguished that could be interpreted as "mathematics," "the nature of science," or even "teaching."

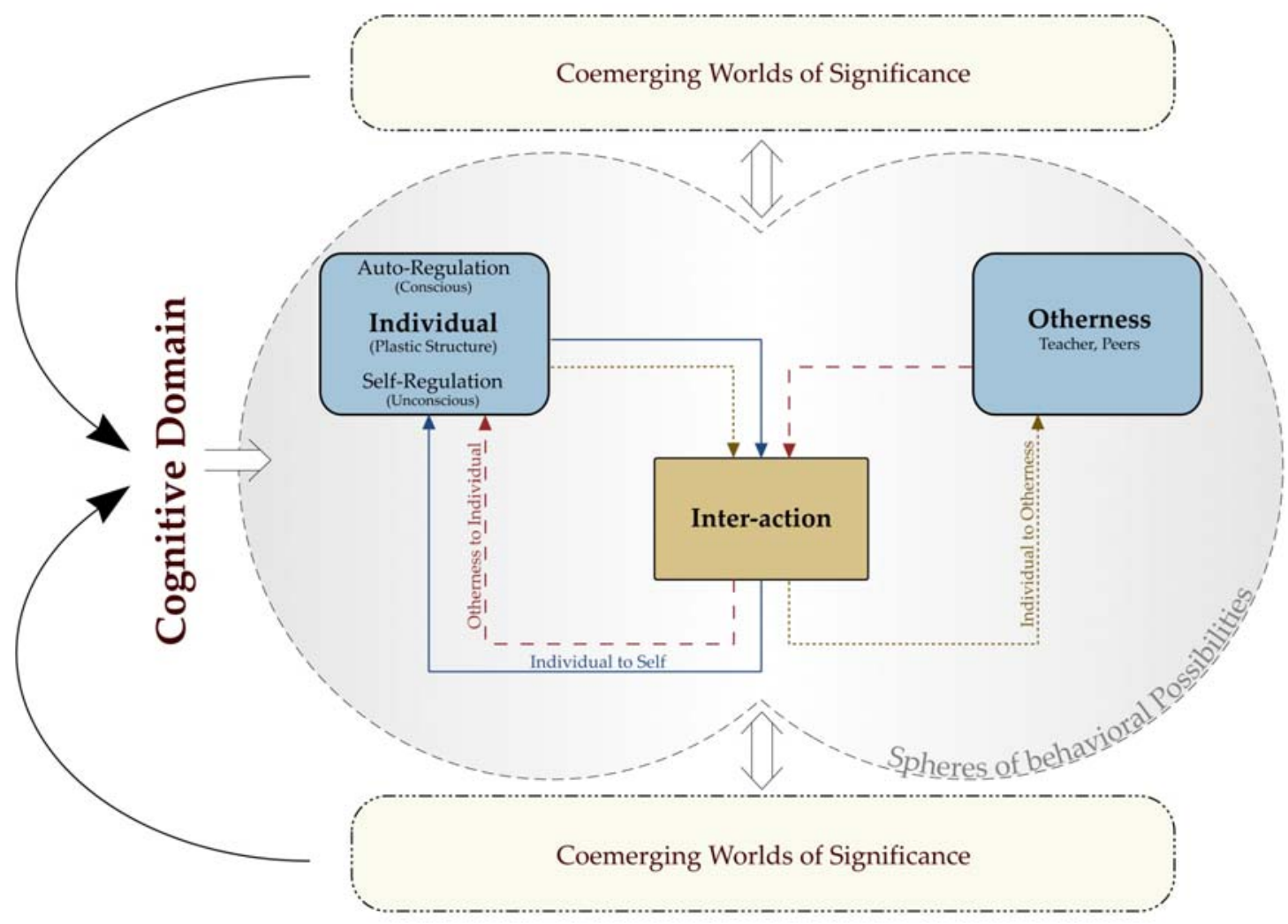

Figure 2. Dynamics of knowing in inter-action (adapted from Simmt, 2000)

This model (Figure 2) highlights the fact that the knowing occurring in a teacher professional development group, such as that which generated the above dialogue sequence, is co-emergent. Such knowing from the point of the individual involves (through self-regulation) the selection and transformation of materials from the "otherness" or from the knower's own re-presentations of prior knowing (see "individual to self" pathway in Figure 2). That is, one's knowing acts are observed to be 
occasioned by the environment including others in it in which the knower exists (see the "otherness to individual" path in Figure 2). But any knowing action which is in any way externalized, made visible to the other, potentially changes the environment and hence is a potential trigger for others and the collective, including the facilitator (see "individual to otherness" path in Figure 2). The model then allows the observer to observe the collective learning system and the individual learner, all-at-once.

In Fazio and Gallagher we read them to imply that in their group the individual knowing was done primarily when each teacher worked on a project in their own classroom and that collective knowing occurred as the group met. As the data in Figure 1 suggests to us, the model (Figure 2) prompts us to see individual knowing occurring continually in the environment of group inter-actions. The model also prompts us to observe the complex recursions occurring in any knowing situation especially those in a collective learning system. In looking at the data above the model provides a mechanism which prompts us to see changes in individual knowing actions which are observed to be occasioned by the actions of others (or by a lived history of such actions, even back in one's own classroom).

The model (Figure 2) also prompts us to ask if there are collective knowings not attributable to an individual (even though an individual may make an utterance) which nevertheless can be seen as occasioned by and arising in the inter-action of individuals. In looking at the teacher interaction above the gist of the conversation can be summarized by noting that measurement differences might arise through differences in the tool (lines $1-13$ ), in the recording (line 6-7), in the measurer (line 23), in the thing being measured (line 32), or the conditions under which it is measured (line 38).

There appear to be two emergent features that have occurred. First although this was not prompted or even suggested formally, the group appears to have changed the problem on which they were working from "which measurement is best" to "what are the sources of differences among measures". Thus a facilitator might observe this collective emergent knowing and ask the group to build on it or to relate it to the previous problem; that is, the facilitator might make special use of such emergent knowing. With respect to Fazio and Gallagher, one of the group's discussions of the nature of science involves their evaluation of their own university science courses as never focusing on this topic. Perhaps this occurred, as was suggested, because the nature of the teaching-learning interaction was not diverse enough or too narrowly focused. Or it might be that while the nature of science ideas emerged in such university classes no one attended to those emergent knowings and hence they went unmarked and unused.

The second emergent phenomenon appears to be qualitatively different from the first. The notion that the object measured could be inconsistent or changing (lines $32-$ 33,38 ) can be observed as being occasioned by the diversity of possibilities offered in the public space and emergent from the interactions of those possibilities. Of course each individual's idea of the emergent idea would necessarily be different, but all members of the group appeared to sense having a new idea in common with the others that could be 
further discussed and used. It transformed how the collective thought about measurement; the sphere of behavioural possibilities for that group grew.

Beyond that the model suggests that inter-action is not only fed by the nature of the cognitive domain in which it exists (for example, the mathematical or scientific ideas which could possibly come into play in the planned teacher development workshop) but emerges and hence is recursively constituted. While this is speculation on our part, the emergent idea that the object measured could be changing might also be observed to change the cognitive domain in which the workshop exists. For example, the facilitator might say, "Let's change our focus here: In what ways can measurements be affected by changes in that which is measured? How about the reverse? Can measuring change the phenomenon being measured?" Of course the first time this latter question arose it had a profound effect of the nature of physics. While we are not suggesting that emergent knowledge arising in inter-actions among teachers would have such dramatic global effects; nonetheless in smaller ways such emerging collective knowledge can change the nature mathematics or science or education at least for the participants and hence the nature of the cognitive domain in which they exist.

By observing teacher development collectives using ideas from complexity theories such as emergence and even designing teacher development with such ideas in mind, Fazio and Gallagher suggest that we get a richer picture of what might go on and what might arise from such collectives. We certainly agree with them on this point. The above discussion offers what we see as a different point of view on emergence as applied in such settings. We read Fazio and Gallagher as focusing on the group formation itself as an emergent phenomenon of the interaction in the group. We believe our example also illustrates the emergence of a collective learning system but our point is that one can see the products of that collective learning system when they have a "project" to work on. A key notion in Maturana and Varela's (1993) theory of cognitive systems is that the system both produces itself and produces products in its world of significance. The above discussion as well as previous work by Davis and Simmt (2003) prompts us to ask Fazio and Gallagher, What were the knowledges (products) or new ways of acting/thinking that emerged in the groups which they studied? In what ways might the interaction of individuals occasion such emergence in your cases?

Our discussion above and the two questions just raised prompt us to consider one further area in this response to Fazio and Gallagher: the nature of the role of the facilitator of such groups. Fazio and Gallagher almost let the nature of the facilitator fade into the background. They emphasize that the facilitators became members of the groups. That is one way to emphasize the decentralization of control or authority in such groups and provide one element of the nature of self-organization in the groups. The latter is one of the central ideas explored in the Fazio-Gallagher essay. But for us saying that the facilitator became a member of the group still leaves the question: what was the nature of the facilitator in the group? In complexity terms, what is the facilitator's specialized role?

It is certainly beyond the scope of our response to look at this in any detail. The model and its pathways above do however point to several kinds of acts in which the 
facilitator of a teacher development collective might well be involved. In developing this brief discussion we follow the work of Varela (1999) who suggests that all actions (and since knowing is acting) have an ethical attachment. Hence we assert that the facilitator's acts necessarily invoke an ethic. Looking at the model and thinking back even to potential uses by the collective of emergent understandings there are at least three kinds of ethical moves which fall to teachers or group facilitators. Using the model we propose it is useful to think of locating the facilitator as (a part of) the "otherness" in the model.

If one considers the pathway otherness to individual, one is led to think about the provisional ethics involved in facilitation. Indeed the facilitator has a special responsibility for providing the teacher collective with appropriate rich materials and tasks. Further, provisional ethics speaks to the manner in which the materials and tasks are provided. In the transcript provided above we observe that the facilitator led the session by offering the task, setting the parameters and "chairing" the discussion; this kind of facilitation should not be thought of as central control of the group. This role description suggests that the facilitator makes an offer but deliberately chooses to select and offer (tasks, questions) in a non-controlling manner. We believe this role is better understood as a specialized role rather than a controlling role. The ethics of such provisional decisions is like onto what we observe to be the non-controlling way in which what the facilitators, discussed in Fazio and Gallagher, provide rich materials for their groups, although this remains only implicit in their paper.

The second kind of ethics suggested by our model is occasional ethics; the action of any person in the collective may occasion the subsequent actions of others and thus influence the knowing of others and the collective. Following the trace of the interaction provided above, one can see the participating teachers giving their own responses in the situation but these responses can be observed to be influenced by others' actions (at least in some instances). Since this effect is very likely to occur from the actions of the facilitator, she has a particular responsibility to take this into account. Perhaps this kind of ethical stance is implicit for Fazio and Gallagher in the facilitator taking the role of one of the group, not as a controller but as a full participant and co-learner.

We name a third kind of ethical action attentional ethics. For the facilitator this points to the choices around listening with ${ }^{1}$ the members of the collective and taking up the ideas on offer in some way. Perhaps the importance of this ethical form of action can be seen in the negative. If the others do not, and particularly if the facilitator does not, attend to the actions of group members there are certainly missed opportunities for growth in collective understanding. Such lack of attention by the facilitator in particular may break the recursive cycle in the group and hence inhibit change in the worlds being brought forth; enlargement of the sphere of behavioural possibilities; and the possibility to take up from and contribute to the cognitive domain. It may be for example, that the university science teachers discussed by group members in the Fazio and Gallagher collectives may have failed to attend to the actions and queries of their students in a way

\footnotetext{
${ }^{1}$ Davis (1996) describes this as hermeneutic listening.
} 
that inhibited ideas on the nature of science from emerging for these classes. In contrast, in the transcript above we observe the facilitator to attend to the comment that a bumpy object may be implicated in the measurement. Her response elaborated the idea when she brought into the conversation the coastline of British Columbia, from which another teacher blurted out that time would also be a factor. This co-emergence of an idea can be traced back to the facilitator "listening" with-demonstrating an attentional ethic.

The import of the above discussion for the Fazio and Gallagher paper is to encourage the authors and the readers alike not to let the role of the facilitator fade into the background. It is critical that control be observed as decentralized in educational situations in order to take advantage of their complexity and complicity, and complexity ideas offer us a way to understand the role of the leader. The facilitator should seek to ensure there is adequate redundancy in the group, there are specialists (including his/herself), there is the public sharing of ideas, strategies, thoughts and finally that the group attend to each other's contributions. As a leader in the group the leader does not say "this is important", "here is how you do this" or "I will do it for you". Rather the leader can point to important things, show how one might do things and leave these for the group to interpret- it is out of such interpretive inter-actions that collective knowledge emerges.

\section{References}

Davis, B. 1996. Teaching mathematics: toward a sound alternative. New York: Garland Publishers.

Davis, B. \& E. Simmt. 2006. Mathematics-for-teaching: An ongoing investigation of the mathematics that teachers (need to) know. Educational Studies in Mathematics 61(3): 293-319.

Davis, B. \& E. Simmt. 2003. Understanding learning systems: mathematics education and complexity science. Journal for Research in Mathematics Education 34(2): 137-167.

Johnson, S. 2001. Emergence: The connected lives of ants, brains, cities, and software. New York: Scribner.

Kerr Stenmark, J., Ed. 1995. 101 short problems from EQUALS. Lawrence Hall of Science, University of California, Berkley, CA.

Maturana, H, \& F. Varela 1993. The tree of knowledge: Biological roots of human understanding. (rev.ed.). Boston: Shambala Publications Inc.

Simmt, E. 2000. Mathematics knowing in action: A fully embodied phenomenon. Unpublished doctoral dissertation, University of Alberta, Edmonton, AB.

Varela, F. 1999. Ethical know-how: Action, wisdom and cognition. Stanford, CA: Stanford University Press.

Acknowledgements

The authors would like to thank Luke Westfall for the preparing the graphic in Figure 2. 


\begin{abstract}
About the Authors
Elaine Simmt is professor and chair of the Department of Secondary Education, University of Alberta. She began her career as a secondary school teacher of mathematics, chemistry and physics and completed doctoral studies under the supervision of Tom Kieren. Her research is focused in mathematics education: in particular she explores teaching and learning through the fame of complexity theory.
\end{abstract}

Tom Kieren is professor emeritus in the Department of Secondary Education, University of Alberta. Probably best know for his seminal work in rational number thinking, Dr. Kieren has had an intense focus on the learner of mathematics. He was one of a very few pioneers of enactivism within the mathematics education community and is arguably one of the most influential mathematics educators in Canada. Today Tom continues his work in mathematics education reviewing dozens of research papers per year and spending hours in his grandchildren's mathematics classrooms as an elder.

(C) Copyright 2009. The authors, TOM KIEREN and ELAINE SIMMT assign to the University of Alberta and other educational and non-profit institutions a non-exclusive license to use this document for personal use and in courses of instruction provided that the article is used in full and this copyright statement is reproduced. The authors also grant a non-exclusive license to the University of Alberta to publish this document in full on the World Wide Web, and for the document to be published on mirrors on the World Wide Web. Any other usage is prohibited without the express permission of the authors. 